\title{
Rationality in the new oxygen evolution catalyst development
}

\author{
Rebecca Pittkowski ${ }^{\mathrm{a}}$, Petr Krtil ${ }^{\mathrm{a}^{*}}$ and Jan Rossmeis ${ }^{\mathrm{b}^{*}}$
}

aJ. Heyrovsky Institute of Physical Chemistry, Czech Academy of Sciences, Dolejskova 3, 18223, Prague, Czech Republic

${ }^{b}$ Department of Chemistry, University Copenhagen, Universitetsparken 5, 2100 København $\varnothing$, Denmark

\section{Abstract}

Anodic oxygen evolution has gained significant prominence in electrochemical research in the last decade in connection with renewable electricity storage. With water being the only available fossil free source of hydrogen, which is deemed the primary storage medium, the water electrolysis optimization is one of the biggest challenges of today's electrochemistry. A development of novel OER catalysts is motivated to increase the feasibility of the current OER catalysts in terms of activity, stability and price. This review summarizes the most recent synthetic approaches in OER catalyst synthesis for acid and alkaline electrolyzers stressing the structural aspects of the proposed catalysts. The reported novel catalyst approaches are aligned with existing theoretical and experiment based descriptors for rational of oxygen evolution activity improvement.

\section{Introduction}

Oxygen evolution reaction (OER) is generally perceived as a sequence of four single electron/proton charge transfer reactions outlined in the equations (1)-(4).

(1) $\mathrm{H}_{2} \mathrm{O}(\mathrm{I})+* \rightleftharpoons \mathrm{HO}^{*}+\mathrm{H}^{+}+\mathrm{e}^{-}$

(2) $\mathrm{HO}^{*} \rightleftharpoons \mathrm{O}^{*}+\mathrm{H}^{+}+\mathrm{e}^{-}$

(3) $\mathrm{O}^{*}+\mathrm{H}_{2} \mathrm{O}(\mathrm{I}) \rightleftharpoons \mathrm{HOO}^{*}+\mathrm{H}^{+}+\mathrm{e}^{-}$

(4) $\mathrm{HOO}^{*} \rightleftharpoons^{*}+\mathrm{O}_{2}(\mathrm{~g})+\mathrm{H}^{+}+\mathrm{e}^{-}$

The energetics of such a reaction sequence on different model surfaces can be computationally assessed.[1] An OER volcano curve can be constructed with the difference in binding energy of the $O$ and $\mathrm{OH}$ intermediate as the reaction descriptor. The apex of the volcano is significantly departed from the position expected for an ideal oxygen evolving catalysts (descriptor is predicted to reach $1.23 \mathrm{eV}$ ). This is a result of the so-called scaling relations[2] which show an inter-dependence of the binding energies of $\mathrm{OH}$ and $\mathrm{OOH}$ intermediates. This restricts synthesis induced improvement of the OER activity via intermediate binding energy control.

Primary motivation of the OER catalyst design is to improve the activity while decreasing catalysts cost. This goal is achieved in majority of the reports on novel catalyst design by comparison with benchmark catalysts' activity. Unfortunately, there is no general agreement on a single benchmark catalysts which demotes the significance of activity improvements reported in the literature. It also needs to be noted that the most synthetic approaches towards OER catalysts are based on a trial and error approach without a rational background guiding the catalysts synthesis. This opinion paper aims at unifying recent approaches reported in OER catalyst synthesis and linking them with existing theory as well as experiment based descriptors of catalyst's OER activity. 


\section{Main review}

Although there have been reports addressing the possible use of transition metal nitrides[3], chalcogenides[4-6] or phosphides[7] as oxygen evolving catalysts [8]. Due to their inherent instability at OER conditions $[9,10]$ the majority of the published reports concentrates on the behaviour and optimization of the transition metal oxides.

The recent reports aiming at improvement of the oxygen evolving catalysts span a wide range of transition metal oxides based on $\mathrm{Mn}, \mathrm{Ir}, \mathrm{Co}, \mathrm{Ni}$ or their composites. The variability of the transition metals in the prospective OER catalysts hinders the generalization of OER activity based on chemical composition. Alternatively, the OER evolving oxides may be classified according to their structural type. It is also convenient to address the catalysts intended for use in acid media separately from those designed for use in alkaline media. The majority of the (crystalline) OER catalysts adheres only to five structural types - four cubic (rock salt, perovskite, spinel and pyrochlore) and one tetragonal (rutile). While catalysts intended for use in acid media conform to rutile and pyrochlore structural types, the majority of catalysts prevailing in alkaline media belong to rock salt, spinel or perovskite structural type.

Development of new OER catalysts follows in principle two distinctive approaches. The first one attempts to increase the number of active sites on the surface. The second aims at improving the catalysts' intrinsic activity. Given the quantitative nature of the first approach, the adopted synthetic strategies aim at optimization of the catalysts' surface by employment of nanostructures, porous materials or controlling the catalyst's morphology.[11,12 The second approach attempts to improve the intrinsic catalysts behaviour by an active control of the active site nature either by doping or via support/catalyst-like effects.

\section{Acid media}

The design of OER catalysts for acid electrolysis is confined primarily to Ru and Ir based oxides. A certain potential can also be demonstrated for catalysts based on $\mathrm{MnO}_{2}$, which also show an acceptable stability in acid media. While ruthenium oxide dominates the theoretical OER volcano, iridium and manganese oxides compensate for a lower activity by catalysts stability or price.

Although $\mathrm{RuO}_{2}$ and $\mathrm{IrO}_{2}$ reside near the apex of the OER volcano their activity can be significantly improved by doping the structure with cobalt or nickel.[13-15] This effect was attributed to activation of $\mathrm{Ni}$ or $\mathrm{Co}$ in bridge-sites which act as a proton donor/acceptor thus allowing breaking the scaling relations.[16] The effect of $\mathrm{Co}$ and $\mathrm{Ni}$ doping is restricted by low attainable doping levels. This drawback can be removed by co-doping with $\mathrm{Ni}$ and $\mathrm{Co}$ mitigating the lattice mismatch experienced for a single dopant. The co-doping reduces the noble metal content in the catalyst down to 50\%.[17] The same principle also applies to the catalyst-substrate effects observed, e.g. for $\mathrm{MnO}_{\mathrm{x}}$ and $\mathrm{CoO}_{\mathrm{x}}$ on $\mathrm{Au}$, where the gold-substrate functions as a hydrogen-transfer site through $\mathrm{Au}=\mathrm{O}$ groups.[18-20]

Similar effects are likely to be at play in composites of $\mathrm{IrO}_{2}$ with transition metal oxides. $\quad \operatorname{IrO} / \mathrm{MoO}_{3}$ composites reportedly possess a higher activity and stability compared to $\mathrm{IrO}_{2}$.[21] Similarly, $1 \mathrm{IO}_{2} / \mathrm{MnO}_{2}$ composites show an increased OER activity due to the strong distortion of $\mathrm{IrO}_{6}$ octahedra by a Jahn Teller effect induced by $\mathrm{MnO}_{2}$. The $\mathrm{IrO}_{6}$ distortion effect is, however, influenced by an increase in surface area.[22] A beneficial effect of Jahn-Teller distortion controlling the $e_{g}$ and $t_{2 g}$ orbital occupancy has been also reported for Cu-doped $\mathrm{IrO}_{2}$.[23] OER activity enhancement via support-catalysts effects were also reported for $\mathrm{IrO}_{2}$ nanoparticles dispersed in $\mathrm{TiO}_{2}$. The OER activity improvement was attributed to the titania stabilizing high iridium oxidation states at the catalysts surface; conversely Ir $^{3+}$ formation is associated with a lower catalyst stability.[24,25] Direct surface modification of $\mathrm{IrO}_{2}$ attained by selective $\mathrm{Sr}$ leaching from $\mathrm{SrIrO}_{3}$ perovskite was also reported to lead to an OER activity improvement.[26] 
Aside from the rutile type $\mathrm{RuO}_{2}$ and $\mathrm{IrO}_{2}$, both transition metals form also cubic conductive oxides of the pyrochlore type $\left(\mathrm{A}_{2} \mathrm{~B}_{2} \mathrm{O}_{7}\right)$ where $\mathrm{Ru} / \mathrm{Ir}$ occupy octahedrally coordinated $\mathrm{B}$ sites and the structure is stabilized by relatively large di or trivalent cations in the $A$ site. $\mathrm{Ru}$ as well as $\mathrm{Ir}$ based pyrochlores were reported to surpass the pure $\mathrm{Ru}$ and $\mathrm{Ir}$ oxides both in terms of activity and stability. The remarkable activity of the $\mathrm{Y}_{2} \mathrm{Ru}_{2} \mathrm{O}_{7}$ was attributed to an unusually low oxidation state of $\mathrm{Ru}$ (+3.3).[27] It needs to be noted, however, that such an oxidation state is not compatible with the pyrochlore structure unless compensated by a significant number of oxygen vacancies. Iridium pyrochlores stabilized by $\mathrm{Y}, \mathrm{Bi}$, and $\mathrm{Pb}$ were also reported to be more active in OER than $\operatorname{IrO}_{2}$. [28] The effect is, however, not very pronounced and may be attributed to selective leaching of the A site cation from the surface in a manner similar to that of the $\mathrm{IrO}_{2} / \mathrm{SrIrO}_{3}$ system.

The Mn based oxides represent the only non-noble metal systems of sufficient stability and activity in acidic media[29]; they are difficult to classify given the rich polymorphism of the manganese oxides. The activity of manganese dioxide-based catalysts can be improved by a control of the oxidation state of $\mathrm{Mn}$ as was show on a comparison of birnessite $\left(\delta-\mathrm{MnO}_{2}\right)$ and hausmannite $\left(\alpha-\mathrm{Mn}_{3} \mathrm{O}_{4}\right)$ based catalysts. The superior activity observed for hausmannite, which attains the spinel structure, is ascribed to a significant $\mathrm{Mn}^{3+}$ content.[30,31] This behaviour, in fact, confirms the theoretical prediction[1], hence the observed activity improvement is achieved within the scope of the existing volcano. Similar principle (altered average oxidation of $\mathrm{Mn}$ ) is expected to be at play for cubic $\mathrm{Cu}_{1.5} \mathrm{Mn}_{1.5} \mathrm{O}_{4}$ and its F-doped variant, which show OER activity comparable to that of $\mathrm{IO}_{2}$. [32]

\section{Alkaline media}

In alkaline media prevail catalyst based on transition metals such as cobalt, nickel, and iron, due to the combination of high activity with low price.[33] The oxides of these transition metals have a tendency to form cubic oxides of either rock salt, spinel or perovskite type.

The activity of the rock salt oxides, such as $\mathrm{NiO}$, is attributed to their transformation to (oxy)hydroxides with layered-structured in-situ under operando conditions.[34] A significant improvement of the OER activity of $\mathrm{Ni}$ and $\mathrm{Co}$ oxide based catalysts was observed in presence of Fe. The origin of this effect is, however, still under debate.[35-37] The highest OER activity was recently described for an amorphous, mesoporous $\mathrm{Ni} / \mathrm{Fe}$ (oxy)hydroxide film on $\mathrm{Ni}$-foam support,[38] which reportedly outperforms (175 mV @50 mA) state-of-the-art Ni-Fe layered double hydroxide nanosheets.[39,40] The origin of these effects has not been fully resolved but may be linked with a different coordination of $\mathrm{Ni}$ inside mesopores and on flat surfaces.[41] The effect of doping of $\mathrm{Ni}$ oxides was investigated also for other transition metal cations. In particular, Pt atoms were found to accelerate the phase transformation to the active $\mathrm{Ni}(\mathrm{OOH})$ affecting positively the OER activity.[42]

Co based catalysts conforming to spinel structures $\left(\mathrm{AB}_{2} \mathrm{O}_{4}\right)$ were investigated in connection with the theoretical prediction of the $\mathrm{CO}_{3} \mathrm{O}_{4}$ position on the OER volcano curve.[1] The highest activity was reported for catalyst with composition of $\mathrm{ZnFe}_{0.4} \mathrm{CO}_{1.6} \mathrm{O}_{4}$. The increase in activity was correlated with an increase of the average oxidation state of Co from 2.86 to 3.34 and consequent higher covalency of Co-O bonds.[43] A similar relation of covalency of Co-O bonds and OER activity was reported for $\mathrm{ZnFeCrO}_{4}$, however, without a concomitant change in the oxidation state of $\mathrm{Co}$.[44] The Co oxidation state strategy of spinel OER improvement is however questioned in operando Raman spectroscopic studies on $\mathrm{Ni}$-modified $\mathrm{CO}_{3} \mathrm{O}_{4}$. These catalysts convert first to amorphous $\mathrm{Ni}$-doped $\alpha$ - $\mathrm{CoO}$ (rock salt) followed by a reversible transition to a complex phase consisting of $\mathrm{NiOOH}$ and layered $\mathrm{CoO}_{2}$ $\left(\mathrm{NiOOH}-\mathrm{h}-\mathrm{COO}_{2}\right) \cdot[45]$.

Lanthanide stabilized transition metal perovskites $\left(\mathrm{ABO}_{3}\right)$ are arguably the best studied structural type of OER catalysts for alkaline media due to variability of structure conforming composition. $[46,47]$ Perovskite activity optimization is directed at the control of the transition metal 
oxidation state. Such an oxidation state optimization was achieved for $\mathrm{Sr}_{1-x} \mathrm{Nb}_{0.1} \mathrm{Co}_{0.7} \mathrm{Fe}_{0.2} \mathrm{O}_{3-\mathrm{d}}$ (SNCF) when A site sub-stoichiometry transforms into a high number of the surface vacancies.[48] An alternative approach leading to an OER activity improvement can be seen in partial substitution of the transition metal cation in $B$ site as reported, e.g., for $\mathrm{SrCo}_{0.4} \mathrm{Fe}_{0.2} \mathrm{~W}_{0.4} \mathrm{O}_{3-\text { d. }}$ [49] Such double perovskites (general formula $\mathrm{A}_{2} \mathrm{~B}^{\prime} \mathrm{B}^{\prime \prime} \mathrm{O}_{6}$ ) allow for ordering of the transition metal cations in the $\mathrm{B}$ site which in turn results in improved OER activity.[50]

An equivocal analysis of the perovskite oxygen evolution activity is further complicated by variability of the oxygen evolution mechanism observed for different perovskites. It was shown that, in the case of $\mathrm{Sr}$ and Ca perovskite based on Fe and Co, the OER mechanism depends on the nature of the B site cation. While the iron based perovskites show no lattice oxygen activation, the cobalt based analogues evolve oxygen primarily by lattice oxygen activation.[51] This behavior was attributed to a hindered oxygen intercalation and larger surface amorphization for the iron-containing structures. The role of the alternative OER mechanisms needs, however, to be re-examined also in the context of the data available for rutile oxides for which lattice oxygen activation complements the conventional OER.[52-53]

\section{Rationalization of the OER catalyst design}

As warrants the large number of papers devoted to oxygen evolution a more generalized approach allowing to streamline the synthetic efforts is needed. Such an approach should allow for a prediction of OER activity of oxides catalysts regardless of their crystal structure or composition. Descriptors are quantities which correlate with the OER activity and which can be obtained with reasonable effort either experimentally or computationally without the need to perform the full OER activity analysis. It is important to realize that many of the descriptors suggested in literature actually are consequences, rather than prediction, of a high activity. Any material quantities measured after OER activity cannot strictly speaking predict activity. Any descriptor, therefore, must be a property of the pristine material. Furthermore, the descriptor must be related to the barrier for the rate determining step of the reaction.

The state-of-the-art descriptor meeting these criterial represents the difference in adsorption energy between the ${ }^{*}-\mathrm{OH}$ and ${ }^{*}=\mathrm{O}$ intermediates.[1] More precise predictions require to complement the model for surface inhomogeneity introducing adjusted coordination numbers.[54] Describing the oxygen evolution activity using the adsorption energies effectively utilizes the d-band centre approach[55] that has proven very successful for electrocatalysis on metals. In a similar manner covalency of the Me-O bond or the oxygen p-band centre have also been proposed as descriptors for OER activity.[56] To combine these approaches, the charge-transfer energy derived from the TM $3 d$ and $O 2 p$ electronic valence states was used as a descriptor.[57] One disadvantage of these electronic structure based descriptors is the lack of immediate feedback to steer synthesis of new catalysts.

Alternative OER activity descriptors based on experimentally assessed data have been proposed. Such descriptors may be exemplified on, e.g. filling of the $e_{g}$ orbital (used for perovskites),[46] the $e_{g}$ occupancy of cations in octahedral sites (used for spinels),[58] or on the relation of the highest occupied d-states to Fermi-level (used for various structures including rock salt, rutile and spinel)[59]. Additional descriptors that have been explored include the catalysts bulk thermochemistry,[60] oxygen vacancies of the catalyst,[61] and the Me-OH bond strength of the adsorbed $\mathrm{OH}$ intermediate.[62,63] Complex descriptors combining the conductivity, oxygen vacancy content, and flat band potential represent the most recent approach in OER descriptor design. [64] It needs to be stressed that the listed examples usually address only catalysts conforming to a single 
structural type and finding experiment based effective descriptor for structurally different OER catalysts remains challenging.

Surprisingly, the local structure of the OER active transition metal cations seems to be underrepresented among the intended OER descriptors compared to those based on band structure. This is counterintuitive given the necessary size compatibility between the active site on the catalyst and the produced oxygen molecule. Local structure data were used in oxygen electrocatalysis to describe the activity trends in the oxygen reduction reaction (ORR) on Pt based alloys. $[65,66]$ It was shown that Pt-Pt distance correlates both with the electronic structure of the catalyst (platinum d-band occupation) and with the observed activity.[66] A similar approach relating the OER activity to Ir-Ir bond-distance was suggested for $\mathrm{IrO}_{2}$ based catalysts.[67] In fact, a similar structure related descriptor was proposed also for $\mathrm{Ni}$ and $\mathrm{Co}$ co-doped iridium oxides.[17] The Ir-Ir bonding distance was, however, replaced by a ratio of the crystallographic unit cell parameters c/a. Although this approach has a certain potential for the catalysts with rutile structure $[15,68]$ it's general applicability is questionable since the trends in c/a parameter reflect rather the clustering of the dopant $[14,68-$ 70] in the rutile structure than the actual change of the binding energetics of the active sites.

The rationale behind the use of Me-Me bond length as a descriptor was ascribed to the varying distance of $\mathrm{OH}$-adsorbates and to the possibility to facilitate the formation of a $\mu$-bridge $\mathrm{O}-\mathrm{O}$ intermediate (see Fig. 1).
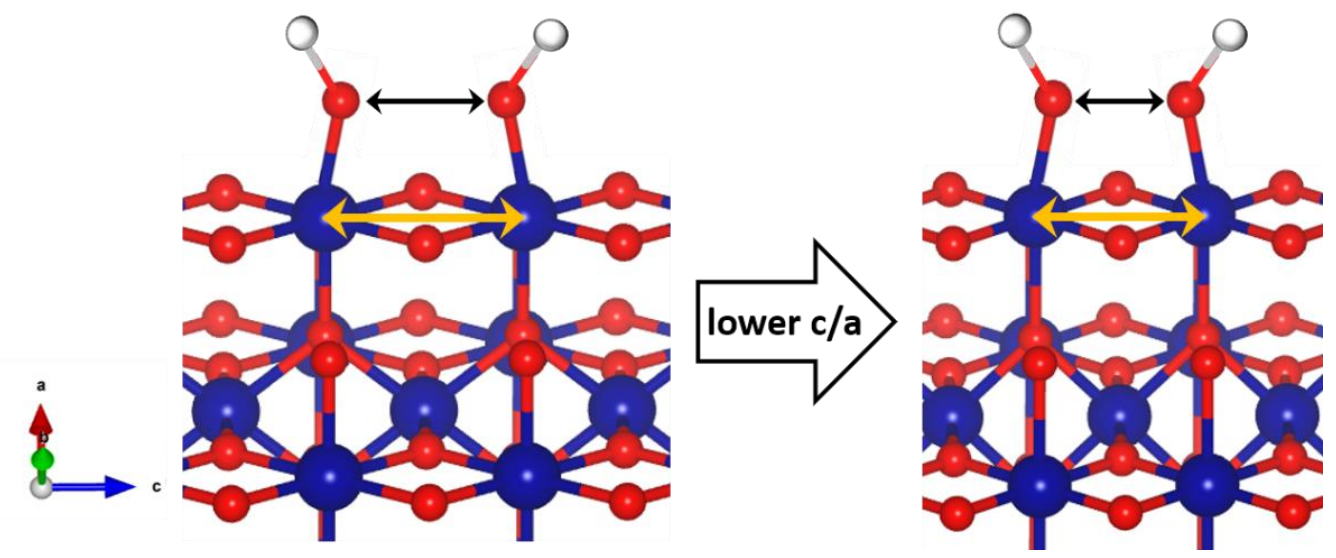

Figure. 1 Schematic drawing of the dependence of a O-O bridge in the metal-metal distance of a rutile type catalyst as a function of the c/a parameter, adapted from [69]. The metal-metal distance is a parameter that can easily be measured using XRD or, to better account for distortions within the material, using XAS ( $\mathrm{x}$-ray absorption spectroscopy).

In fact, a formation of stable surface confined peroxo $\mu$-bridge has been predicted by DFT for a relatively broad range of the transition metal oxides in a relatively broad range of potentials. One may extend the use of the Me-Me bond length descriptor outside of the rutile type oxides namely to cubic systems where one can use the chemical composition to effectively alter the local structure. Applying the same approach to rationalize OER trends of cubic oxides of pyrochlore or perovskite structure one obtains the rather nicely correlating trend as depicted in Figure 2. 


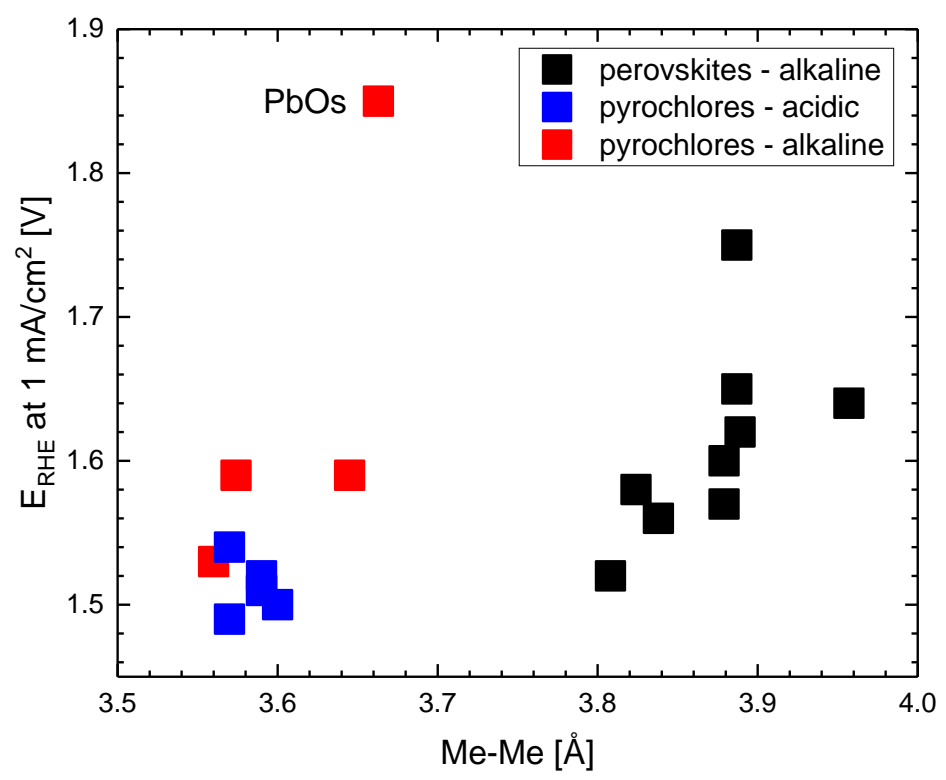

Figure 2 Catalyst activity, depicted as potential necessary to drive the current density to $1 \mathrm{~mA} / \mathrm{cm}^{2}$, as a function of Metal-Metal distance. Values were taken from the literature: Lanthanide perovskite from ShaoHorn et al.[47] (Me-Me from XRD, E from tafel slope), $\mathrm{Y} / \mathrm{Bi} / \mathrm{Pb}$ iridium pyrochlores in acidic media from Schmidt et al. [29] (Me-Me from XAS, E from tafel slope), Bi/Pb pyrochlores in alkaline media from Ramani et al. [71] (Me-Me from XRD, E from CV).

It needs to be noted that fairly similar trends can be tracked for catalysts belonging to both structural types. This can be ascribed to reasonably similar particle size of all included catalysts which were prepared by high-temperature syntheses exceeding $1000{ }^{\circ} \mathrm{C}$. It needs to be noted that the OER activity trend holds apparently also for perovskite-based catalysts which are confined to alkaline media where no theoretical prediction of peroxo $\mu$-bridge exists.

\section{Conclusions}

It needs to be noted that although the experimentally accessible descriptors related to structure show a potential as an immediate feedback in synthesis they are not yet equivalent to the descriptors based on the electronic structure. Despite satisfactory correlation with OER activity they do not point immediately towards optimal catalyst. They may, however, act synergetically with theoretical prediction tools namely in further optimization of theoretically pre-selected catalysts. The importance of the successful implementation of theoretical and experimental descriptors is highlighted by extent of the experimental efforts devoted to synthesis of new OER catalysts. It can be predicted that the rational use of the descriptors will be pre-requisite for development of industry grade catalysts for large scale deployment.

Acknowledgement:

The authors appreciate the support of the European Commission within the framework of the Innovative Training Network Elcorel (Contract 722614). 
References

1. I.C. Man, H.YY. Su, F. Calle-Vallejo, H.A. Hansen, J.I. Martínez, N.G. Inoglu, J. Kitchin, T.F. Jaramillo, J.K. Nørskov, J. Rossmeisl, Universality in Oxygen Evolution Electrocatalysis on Oxide Surfaces, ChemCatChem. 3 (2011) 1159-1165.

2. J. Rossmeisl, A. Logadottir, J.K. Nørskov, Electrolysis of water on (oxidized) metal surfaces, Chem. Phys. 319 (2005) 178-184.

3. K. Xu, P. Chen, X. Li, Y. Tong, H. Ding, X. Wu, W. Chu, Z. Peng, C. Wu, Y. Xie, Metallic Nickel Nitride Nanosheets Realizing Enhanced Electrochemical Water Oxidation, J. Am. Chem. Soc. 137 (2015) 4119-4125.

4. C. Tang, Z. Pu, Q. Liu, A.M. Asiri, X. Sun X, $\mathrm{NiS}_{2}$ nanosheets array grown on carbon cloth as an efficient 3D hydrogen evolution cathode. Electrochim. Acta 153 (2015) 508-514.

5. Y. Liu, H. Cheng, M. Lyu, S. Fan, Q. Liu, W. Zhang, Y. Zhi, C. Wang, C. Xiao, S. Wei, et al., Low Overpotential in Vacancy-Rich Ultrathin $\mathrm{CoSe}_{2}$ Nanosheets for Water Oxidation. J. Am. Chem. Soc. 136 (2014) 15670-15675.

6. Q. Gao, C-Q. Huang, Y-M. Ju, M-R. Gao, J-W. Liu, D. An, C-H. Cui, Y-R. Zheng, W-X. Li, S-H. Yu, Phase-Selective Syntheses of Cobalt Telluride Nanofleeces for Efficient Oxygen Evolution Catalysts, Angew Chem. Int. Ed. 56 (2017) 7769-7773.

7. X. Wang, Y.V. Kolen'ko, L. Liu, Direct solvothermal phosphorization of nickel foam to fabricate integrated Ni2P-nanorods/Ni electrodes for efficient electrocatalytic hydrogen evolution. Chem. Comm. 51 (2015) 6738-6741.

8. S. Anantharaj, S.R. Ede, K. Sakthikumar, K. Karthick, S. Mishra, S. Kundu, Recent Trends and Perspectives in Electrochemical Water Splitting with an Emphasis on Sulfide, Selenide, and Phosphide Catalysts of Fe, Co, and Ni: A Review, ACS Catal. 6 (2016) 8069-8097.

9. L.A. Stern, L. Feng, F. Song, $\mathrm{X}$. $\mathrm{Hu}, \mathrm{Ni}_{2} \mathrm{P}$ as a Janus catalyst for water splitting: The oxygen evolution activity of $\mathrm{Ni}_{2} \mathrm{P}$ nanoparticles. Energy Environ. Sci. 8 (2015) 2347-2351.

10. S. Jin, Are Metal Chalcogenides, Nitrides, and Phosphides Oxygen Evolution Catalysts or Bifunctional Catalysts? ACS Energy Lett. 2 (2017) 1937-1938.

11. Q. Wang, K. Dastafkan, C. Zhao, Design strategies for non-precious metal oxide electrocatalysts for oxygen evolution reactions. Curr. Opin. Electrochem. 10 (2018) 16-23.

12. Z. Chen, C.X. Kronawitter, B.E. Koel, Facet-dependent activity and stability of Co3O4 nanocrystals towards the oxygen evolution reaction, Phys. Chem. Chem. Phys. 17 (2015) 29387-29393.

13. K. Macounova, M.V. Makarova, P. Krtil, Oxygen evolution on nanocrystalline RuO2and

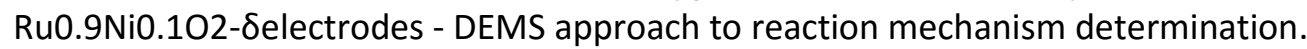
Electrochem. Commun. 11 (2009) 1865-1868.

14. V. Petrykin, K. Macounová, M. Okube, S. Mukerjee, P. Krtil, Local structure of Co doped RuO2 nanocrystalline electrocatalytic materials for chlorine and oxygen evolution. Catal. Today 202 (2013) 63-69.

15. M.V. Makarova, J. Jirkovský, M. Klementová, I. Jirka, K. Macounová, P. Krtil, The electrocatalytic behavior of $\mathrm{Ru}_{0.8} \mathrm{Co}_{0.2} \mathrm{O}_{2-\mathrm{x}}$ the effect of particle shape and surface composition. Electrochim. Acta. 53 (2008) 2656-2664. 
16. *N.B. Halck, V. Petrykin, P. Krtil, J. Rossmeisl, Beyond the volcano limitations in electrocatalysis - oxygen evolution reaction. Phys. Chem. Chem. Phys. 16 (2014) 1368213688.

17. W.Q. Zaman, Z. Wang, W. Sun, Z. Zhou, M. Tariq, L. Cao, X-Q. Gong, J. Yang, Ni-Co Codoping Breaks the Limitation of Single-Metal-Doped $\mathrm{IrO}_{2}$ with Higher Oxygen Evolution Reaction Performance and Less Iridium. ACS Energy Lett. 2 (2017) 2786-2793.

18. *R. Frydendal, M. Busch, N.B. Halck, E.A. Paoli, P. Krtil, I. Chorkendorff, J. Rossmeisl, Enhancing Activity for the Oxygen Evolution Reaction: The Beneficial Interaction of Gold with Manganese and Cobalt Oxides. ChemCatChem 7 (2015) 149-154.

19. Y. Gorlin, C-J. Chung, J.D. Benck, D. Nordlund, L. Seitz, T-C. Weng, D. Sokaras, B.M. Clemens, T.F. Jaramillo, Understanding Interactions between Manganese Oxide and Gold That Lead to Enhanced Activity for Electrocatalytic Water Oxidation. J. Am. Chem. Soc. 136 (2014) 49204926.

20. B.S. Yeo, A.T. Bell, Enhanced Activity of Gold-Supported Cobalt Oxide for the Electrochemical Evolution of Oxygen,. J. Am. Chem. Soc. 133 (2011) 5587-5593.

21. M. Tariq, W.Q. Zaman, W. Sun, Z. Zhou, Y. Wu, L. Cao, J. Yang, Unraveling the Beneficial Electrochemistry of $\mathrm{IrO} / 2 / \mathrm{MoO}_{3} \mathrm{Hybrid}$ as a Highly Stable and Efficient Oxygen Evolution Reaction Catalyst. ACS Sustain. Chem. Eng. 6 (2018) 4854-4862.

22. Z. Zhou, W.Q. Zaman, W. Sun, L. Cao, M. Tariq, J. Yang, Cultivating crystal lattice distortion in IrO $\mathrm{O}_{2}$ via coupling with $\mathrm{MnO}_{2}$ to boost the oxygen evolution reaction with high intrinsic activity. Chem. Commun. 54 (2018) 4959-4962.

23. W. Sun, Y. Song, X-Q. Gong, L. Cao, J. Yang, An efficiently tuned d-orbital occupation of IrO2 by doping with Cu for enhancing the oxygen evolution reaction activity. Chem. Sci. 6 (2015) 4993-4999.

24. E. Oakton, D. Lebedev, M. Povia,D.F. Abbott, E. Fabbri, A. Fedorov, M. Nachtegaal, C. Copéret, T.J. Schmidt, $\mathrm{IrO}_{2}-\mathrm{TiO}_{2}$ : A High-Surface-Area, Active, and Stable Electrocatalyst for the Oxygen Evolution Reaction. ACS Catal. 7 (2017) 2346-2352.

25. D.F. Abbott, D. Lebedev, K. Waltar, M. Povia, M. Nachtegaal, E. Fabbri,C. Copéret, T.J. Schmidt , Iridium Oxide for the Oxygen Evolution Reaction: Correlation between Particle Size, Morphology, and the Surface Hydroxo Layer from Operando XAS. Chem. Mater. 28 (2016) 6591-6604.

26. *L.C. Seitz, C.F. Dickens, K. Nishio, Y. Hikita, J. Montoya, A. Doyle, C. Kirk, A. Vojvodic, H.Y. Hwang, J.K. Norskov, et al., A highly active and stable $\mathrm{IrO}_{x} / \mathrm{SrlrO}_{3}$ catalyst for Oxygen Evolution Reaction. Science 353 (2016) 1011-1014.

27. J. Kim, P.C. Shih, K.C. Tsao, Y.T. Pan, X. Yin, C.J. Sun, H. Yang, High-Performance PyrochloreType Yttrium Ruthenate Electrocatalyst for Oxygen Evolution Reaction in Acidic Media. J. Am. Chem. Soc. 139 (2017) 12076-12083.

28. D. Lebedev, M. Povia, K. Waltar, P.M. Abdala, I.E. Castelli, E. Fabbri, M.V. Blanco, A. Fedorov, C Copéret, N. Marzari et al., Highly Active and Stable Iridium Pyrochlores for Oxygen Evolution Reaction. Chem. Mater. 29 (2017) 5182-5191.

29. M. Huynh, D.K. Bediako, D.G. Nocera, A Functionally Stable Manganese Oxide Oxygen Evolution Catalyst in Acid. J. Am. Chem. Soc. 136 (2014) 6002-6010.

30. M. Huynh, C. Shi, S.J.L. Billinge, D.G. Nocera, Nature of Activated Manganese Oxide for Oxygen Evolution, J. Am. Chem. Soc. 137 (2015) 14887-14904. 
31. *Z. Morgan Chan, D.A. Kitchaev, J. Nelson Weker, C. Schnedermann, K. Lim, G. Ceder, W. Tumas, M.F. Toney, D.G. Nocera, Electrochemical trapping of metastable $\mathrm{Mn}^{3+}$ ions for activation of $\mathrm{MnO}_{2}$ oxygen evolution catalysts. PNAS 115 (2018) E5261-E5268.

32. P.P. Patel, M.K. Datta, O.I. Velikokhatnyi, R. Kuruba, K. Damodaran, P. Jampani, B. Gattu, P.M. Shanthi, S.S. Damle, P.N. Kumta, Noble metal-free bifunctional oxygen evolution and oxygen reduction acidic media electro-catalysts, Sci. Rep. 6 (2016) 1-14.

33. C.C.L. McCrory, S. Jung, J.C. Peters, T.F. Jaramillo, Benchmarking Heterogeneous Electrocatalysts for the Oxygen Evolution Reaction. J. Am. Chem. Soc. 135 (2013) 1697716987.

34. M.S. Burke, L.J. Enman, A.S. Batchellor, S. Zou, S.W. Boettcher, Oxygen Evolution Reaction Electrocatalysis on Transition Metal Oxides and (Oxy)hydroxides: Activity Trends and Design Principles. Chem. Mater. 27 (2015) 7549-7558.

35. D. Friebel, M.W. Louie, M. Bajdich, K.E. Sanwald, Y. Cai, A.M. Wise, M.J. Cheng, D. Sokaras, T.C. Weng, R. Alonso-Mori, et al., Identification of highly active Fe sites in (Ni,Fe)OOH for electrocatalytic water splitting. J. Am. Chem. Soc. 137 (2015) 1305-1313.

36. N. Li, D.K. Bediako, R.G. Hadt, D. Hayes, T.J. Kempa, F. von Cube, D.C. Bell, L.X. Chen, D.G. Nocera, Influence of iron doping on tetravalent nickel content in catalytic oxygen evolving films. PNAS 114 (2017) 1486-1491.

37. H. Xiao, H. Shin, W.A. Goddard III, Synergy between Fe and Ni in the optimal performance of (Ni,Fe)OOH catalysts for the oxygen evolution reaction. PNAS 115 (2018) 5872-5877.

38. H. Zhou, F. Yu, Q. Zhu, J. Sun, F. Qin, L. Yu, J. Bao, Y. Yu, S. Chen, Z. Ren, Water splitting by electrolysis at high current densities under 1.6 volts, Energy Environ. Sci. 2018, doi:10.1039/C8EE00927A.

39. X. Long, J. Li, S. Xiao, K. Yan, Z. Wang, H. Chen, S. Yang, A strongly coupled graphene and FeNi double hydroxide hybrid as an excellent electrocatalyst for the oxygen evolution reaction, Angew. Chem. Int. Ed. 53 (2014) 7584-7588.

40. X. Xu, F. Song, X. Hu, A nickel iron diselenide-derived efficient oxygen-evolution catalyst, Nature Commun. 7 (2016) 1-7.

41. F. Calle-Vallejo, J. Tymoczko, V. Colic, Q.H. Vu, M.D. Pohl, K. Morgenstern, D. Loffreda, P. Sautet, W. Schuhmann, A.S. Bandarenka, Finding optimal surface sites on heterogeneous catalysts by counting nearest neighbors, Science 350 (2015) 185-190.

42. C. Lin, Y. Zhao, H. Zhang, S. Xie, Y-F. Li, X. Li, Z. Jiang, Z-P. Liu, Accelerated active phase transformation of $\mathrm{NiO}$ powered by $\mathrm{Pt}$ single atoms for enhanced oxygen evolution reaction, Chem. Sci. 9 (2018) 6803-6812.

43. Y. Zhou, S. Sun, J. Song, S. Xi, B. Chen, Y. Du, A.C. Fisher, F. Cheng, X. Wang, H. Zhang, et al, Enlarged Co-O Covalency in Octahedral Sites Leading to Highly Efficient Spinel Oxides for Oxygen Evolution Reaction, Adv. Mater. 30 (2018) 1802912.

44. H. Li, S. Sun, S. Xi, Y. Chen, T. Wang, Y. Du, M. Sherburne, J.W. Ager, A.C. Fisher, Z.J. Xu, Metaloxygen Hybridization Determined Activity in Spinel-based Oxygen Evolution Catalysts: A Case Study of $\mathrm{ZnFe}_{2-x} \mathrm{Cr}_{x} \mathrm{O}_{4}$, Chem. Mater (2018) doi:10.1021/acs.chemmater.8b02871.

45. Z. Chen, L. Cai, X. Yang, C. Kronawitter, L. Guo, S. Shen, B.E. Koel, Reversible Structural Evolution of $\mathrm{NiCoO}_{x} \mathrm{H}_{y}$ During the Oxygen Evolution Reaction and Identification of the Catalytically Active Phase. ACS Catal. 8 (2018) 1238-1247.

46. J. Suntivich, K.J. May, H.A. Gasteiger, J.B. Goodenough, Y. Shao-Horn, A perovskite oxide 
optimized for oxygen evolution catalysis from molecular orbital principles, Science 334 (2011) 1383-1385.

47. J. Hwang, R.R. Rao, L. Giordano, Y. Katayama, Y. Yu, Y. Shao-Horn, Perovskites in catalysis and electrocatalysis. Science 358 (2017) 751-756.

48. H. Liu, X. Ding, L. Wang, D. Ding, S. Zhang, G. Yuan, Cation deficiency design: A simple and efficient strategy for promoting oxygen evolution reaction activity of perovskite electrocatalyst, Electrochim. Acta 259 (2018) 1004-1010.

49. G. Chen, Z. Hu, Y. Zhu, Z-G. Chen, Y. Zhong, H-J. Lin, C-T. Chen, L.H. Tjeng, W. Zhou, Z. Shao, Ultrahigh-performance tungsten-doped perovskites for the oxygen evolution reaction. J. Mater. Chem. A 6 (2018) 9854-9859.

50. H. Sun, G. Chen, Y. Zhu, B. Liu, W. Zhou, Z. Shao, B-Site Cation Ordered Double Perovskites as Efficient and Stable Electrocatalysts for Oxygen Evolution Reaction, Chem. Eur. J. 23 (2017) 5722-5728.

51. *B. Han, A. Grimaud, L. Giordano, W.T. Hong, O. Diaz-Morales, L. Yueh-Lin, J. Hwang, N. Charles, K.A. Stoerzinger, W. Yang et al., Iron-Based Perovskites for Catalyzing Oxygen Evolution Reaction J. Phys. Chem. C 122 (2018) 8445-8454.

52. S. Fierro, T. Nagel, H. Baltruschat, C. Comninellis, Investigation of the oxygen evolution reaction on $\mathrm{Ti} / \mathrm{IrO}_{2}$ electrodes using isotope labelling and on-line mass spectrometry. Electrochem. Commun. 9 (2007) 1969-1974.

53. K. Macounova,M.V. Makarova, P. Krtil, Oxygen evolution on nanocrystalline $\mathrm{RuO}_{2}$ and $\mathrm{Ru}_{0.9} \mathrm{Ni}_{0.1} \mathrm{O}_{2-\delta}$ electrodes - DEMS approach to reaction mechanism determination, Electrochem. Commun 11 (2009) 1865-1868.

54. *V. Fung, F.F. Tao, D. Jiang, General Structure-Reactivity Relationship for Oxygen on Transition-Metal Oxides, J. Phys. Chem. Lett. 8 (2017) 2206-2211.

55. J.K. Norskov, F. Abild-Pedersen, F. Studt, T. Bligaard, Density functional theory in surface chemistry and catalysis, PNAS 108 (2011) 937-943.

56. A. Grimaud, W.T. Hong, Y. Shao-Horn, J.M. Tarascon, Anionic redox processes for electrochemical devices, Nature Mater. 15 (2016) 121-126.

57. *W. Hong, K.A. Stoerzinger, Y-L. Lee, L. Giordano, A.J.L. Grimaud, A.M. Johnson, J. Hwang, E. Crumlin, W. Yang, Y. Shao-Horn, Charge-transfer-energy-dependent oxygen evolution reaction mechanisms for perovskite oxides, Energy Environ. Sci. 10 (2017) 2190-2200.

58. C. Wei, Z. Feng, G.G. Scherer, J. Barber, Y. Shao-Horn, Z.J. Xu, Cations in Octahedral Sites: A Descriptor for Oxygen Electrocatalysis on Transition-Metal Spinels, Adv Mater. 29 (2017) 1606800 .

59. H.B. Tao, L. Fang, J. Chen, H.B. Yang, J. Gao, J. Miao, S. Chen, B. Liu B, Identification of Surface Reactivity Descriptor for Transition Metal Oxides in Oxygen Evolution Reaction, J. Am. Chem. Soc. 138 (2016) 9978-9985.

60. F. Calle-Vallejo, O.A. Díaz-Morales, M.J. Kolb, M.T.M. Koper, Why is Bulk Thermochemistry a Good Descriptor for the Electrocatalytic Activity of Transition Metal Oxides? ACS Catal. 5 (2015) 869-873.

61. J.T. Mefford, X. Rong, A.M. Abakumov, W.G. Hardin, S. Dai, A.M. Kolpak, K.P. Johnston, K.J. Stevenson, Water electrolysis on $\mathrm{La}_{1-x} \mathrm{Sr}_{x} \mathrm{CoO}_{3-\delta}$ perovskite electrocatalysts. Nature Commun 2016) 1-11. 
62. L. Liardet, X. Hu, Amorphous Cobalt Vanadium Oxide as a Highly Active Electrocatalyst for Oxygen Evolution, ACS Catal. 8 (2018) 644-650.

63. C.G. Morales-Guio, L. Liardet, X. Hu, Oxidatively Electrodeposited Thin-Film Transition Metal (Oxy)hydroxides as Oxygen Evolution Catalysts, J. Am. Chem. Soc. 138 (2016), 8946-8957.

64. X. Cheng, E. Fabbri, Y. Yamashita, I. Castelli, B.J. Kim, M. Uchida, R. Haumont, I. Puente Orench, T.J. Schmidt, Oxygen Evolution Reaction on Perovskites: A Multi-Effect Descriptors Study Combining Experimental and Theoretical Methods, ACS Catal. (2018) doi:10.1021/acscatal.8b02022.

65. S. Mukerjee, Role of Structural and Electronic Properties of Pt and Pt Alloys on Electrocatalysis of Oxygen Reduction, J. Electrochem. Soc. 142 (1995) 1409-1422.

66. M. Escudero-Escribano, P. Malacrida, H.M. Hansen, U.G. Vej-Hansen, A. Velazquez-Palenzuela, V. Tripkovic, J. Schiøtz, J. Rossmeisl, I.E.L. Stephens, I. Chorkendorff, Tuning the activity of Pt alloy electrocatalysts by means of the lanthanide contraction, Science 352 (2016) 73-76.

67. W. Sun, Z. Wang, W.Q. Zaman, Z. Zhou, L. Cao, X-Q. Gong, J. Yang, Effect of lattice strain on the electro-catalytic activity of $\mathrm{IrO}_{2}$ for water splitting, Chem. Comm. 54 (2018) 996-999.

68. V. Petrykin, Z. Bastl, J. Franc, K. Macounova, M.V. Makarova, S. Mukerjee, N. Ramaswamy, I. Spirovova, P. Krtil, Local Structure of Nanocrystalline $\mathrm{Ru}_{1-x} \mathrm{Ni}_{x} \mathrm{O}_{2-\delta}$ Dioxide and Its Implications for Electrocatalytic Behavior-An XPS and XAS Study. J. Phys. Chem. C 113 (2009) 2165721666.

69. D.F. Abbott, S. Mukerjee, V. Petrykin, Z. Bastl, N.B. Halck, J. Rossmeisl, P. Krtil, Oxygen reduction on nanocrystalline ruthenia - local structure effects, RSC Adv. 5 (2015) 1235-1243.

70. V. Petrykin, K. Macounova, J. Franc, O. Shlyakhtin, M. Klementova, S. Mukerjee, P. Krtil, Zndoped $\mathrm{RuO}_{2}$ electrocatalyts for Selective Oxygen Evolution: Relationship between Local Structure and Electrocatalytic Behavior in Chloride Containing Media, Chem. Mater 2011) 200-207.

71. J. Parrondo, M. George, C. Capuano, K.E. Ayers, V. Ramani, Pyrochlore electrocatalysts for efficient alkaline water electrolysis. J. Mater. Chem. A 3 (2015) 10819-10828. 